\title{
Pediatric Otological Disorders: An In-Hospital Study
}

\author{
Dipak Kumar Gupta, ${ }^{1}$ Poonam Kumari Shah ${ }^{2}$ \\ ${ }^{1}$ Department of Pediatrics, Janaki Medical College, Janakpur, Nepal; \\ ${ }^{2}$ Department of Community Medicine, Janaki Medical College, Janakpur, Nepal.
}

\begin{abstract}
Introduction: Social factors influencing the likelihood of developing pediatric Ear, Nose and Throat (ENT) disorders include socioeconomic status, the type of family, overcrowding, and access to health care, which are prevalent in developing countries like Nepal. Nepalese populations are not well documented with regards to pediatric ENT disorders.

Objective: The aim of the study was to determine the prevalence of ENT disorders in pediatric patients attending hospitals.

Methods: This is a cross-sectional descriptive study that which was conducted at Janaki Medical College, Janakpur between January and September of 2021. Consecutive children from Janaki Medical College between the ages of 6 months and 18 years with otological complaints participated in the study. Afterward, the diagnosis was derived from patients' OPD cards or by contacting them by phone.

Results: The mean ages of male and female participants were $3.2 \pm 2.7$ years old and $4.9 \pm 2.6$ years respectively. Out of the study participants who complained about otological complaints, the majority (37.45\%) had ear wax on their ears, followed by foreign bodies (21.30\%) and acute otitis externa (9.2\%). Among foreign bodies encountered, rubber (35.48\%) was most common, followed by seed (24.19\%).
\end{abstract}

Conclusions: Pediatric ear diseases are very common. In the majority of cases, ear wax and foreign bodies were found. By raising awareness about ear hygiene and disease, we can reduce the problems associated with them.

Keywords: Ear, Nose and Throat; otology; pediatric; Prevalence.

\section{INTRODUCTION}

The World Health Organization estimates 32 million children have a disabling hearing loss worldwide, most of them in developing nations. ${ }^{1}$ A common childhood condition involving hearing loss is cerumen impaction and chronic otitis media. ${ }^{2,3}$ Children are predisposed to otological disorders due to their anatomical, physiological, and immunological characteristics. Children have a short and horizontal eustachian tube with reduced rigidity. When the nasopharynx gets infected with a viral

Correspondence
Dr. Dipak Kumar Gupta
Email: drdipakkumargupta@gmail.com
Citation
Gupta DK, Shah PK. Pediatric Otological Disorders: An In-Hospital
Study. Nepal J Health Sci. 2021 Jul-Dec; 1(2): 23-6.

infection, bacteria may colonize the nasopharynx and then ascend through the eustachian tube causing otitis media. $^{4}$

Hearing-impaired children perform worse academically, are less likely to attend secondary school, and are more likely to be unemployed as adults. The barriers to achieve quality education for all may include evidence of pediatric hearing loss. Nearly half of French children in a study with moderate hearing loss reported one or more years of grade retention. A better understanding of the burden of hearing loss requires a discussion of its prevalence and etiology. However, data indicates $60 \%$ of pediatric hearing loss is preventable, despite the current dismal state of the situation. Besides primary prevention, early detection and treatment can ensure of better social and educational 
outcomes. ${ }^{5}$ This study was conducted to determine the prevalence and characteristics of common ear disorders in pediatric patients making hospital visits for ear complaints.

\section{METHODS}

A cross-sectional descriptive study was conducted at Janaki Medical College in Janakpur between January and July of 2021. We recruited consecutive patients from the pediatric department of Janaki Medical College between the ages of 6 months and 18 years for the study. Informed consent was obtained from the parents. A structured questionnaire focusing on symptoms was administered to the patient's parents after that the patients were physically examined. We referred patients with any apparent audiological pathology to an otorhinolaryngologist. The diagnosis was then obtained from the patient's OPD card or by contacting patients on a phone call. Using Excel as a data entry tool, and IBM SPSS version 20 as an analysis tool, data was entered. The categorical data were expressed in percentage, whereas continuous data were expressed in mean $\pm \mathrm{SD}$.

\section{RESULTS}

Throughout the study, we recruited 291 patients who came to the Pediatric department at Janaki Medical College with otological complaints. A majority of $82(54 \%)$ of those recruited were male, while 68 $(46 \%)$ were female. Ages ranged from eight months to sixteen years. The mean age of males was $3.2 \pm$ 2.7 years and the mean age of females was $4.9 \pm 2.6$ years.

Otological complaints in pediatric patients were most commonly associated with ear wax (37.45\%), followed by foreign bodies (21.30\%). Mastoid abscess was the least common finding (Figure 1).

The most common foreign bodies removed from ears were rubber/ erasers, followed by seeds (Figure 2).

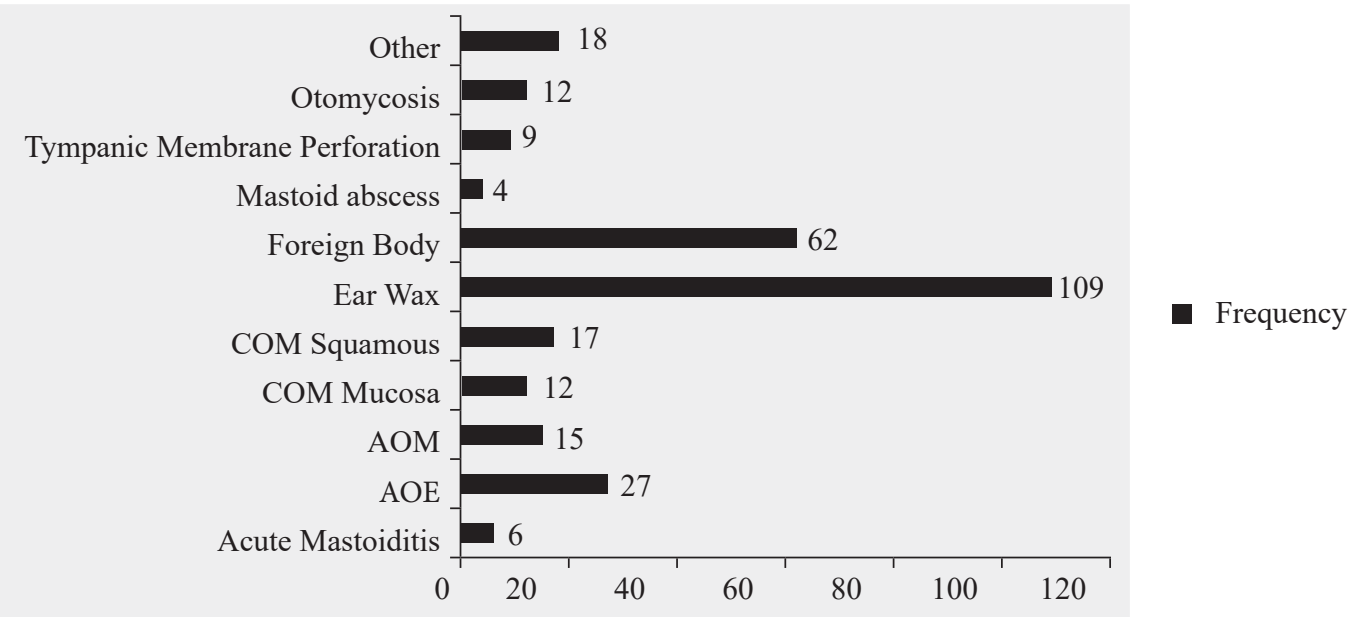

Figure 1: Pattern of otological disorders in pediatric population.

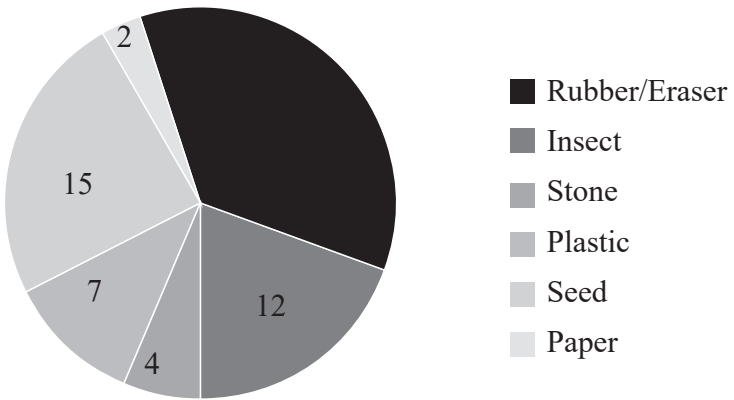

Figure 2: Type of foreign body. 


\section{DISCUSSION}

The burden of otologic complaints in Nepal has been largely overlooked, especially in the pediatric population. Here, we provide contemporary descriptions of otologic complaints common during an emergency department visit or in the pediatric outpatient clinic. Research and policy on public health frequently overlook these diseases in pediatric diagnostic categories. There is clearly a great burden of otological disorders in pediatric patients, judging from the number of cases presenting to the hospital within such a short time period.

A high prevalence of ear wax was observed in the current study. An investigation into the incidence of ENT disorders among pediatric patients carried out by Nepali et $\mathrm{al}^{6}$ from Gandaki Medical College in Nepal brought about similar findings with prevalence of $40.9 \%$. Several studies conducted in Nepal have shown that ear wax is common among otological complaints ranging from 29.15 to $60.6 \%{ }^{7,8}$ There could be an underlying explanation for such a high prevalence of ear wax, because most people ignore it because they do not experience any symptoms; therefore, they do not seek medical attention. Also, several factors play a role in the production of wax, including humidity, temperature, and race.

A slight male preponderance was present in this study, although we were unable to determine the reasons, however it was similar to those in other studies. ${ }^{6,9}$

Children between the ages of 0 and 5 were most affected. This may be due to the closer monitoring by caregivers necessitated by their young age, which leads to early medical attention being sought at the slightest sign of discomfort. Unlike Nepal et al., ${ }^{6}$ found that children aged 6-10 were the most affected.

The second most common finding in our study participants was ear foreign body. The fact that we are the largest provider of health care in Janakpur may account for the large number of foreign bodies seen in our hospital. Otitis media, in contrast, was the second most common finding in earlier studies. ${ }^{6-}$ ${ }^{8} \mathrm{An}$ assessment of pediatric emergency cases by Nisar et al. found that aural foreign body was the most common cause of medical care for otological complaints. ${ }^{10}$ This suggests that a child experiences a period of curiosity as they explore their environment and body. The foreign bodies are inserted as quickly as possible, without the presence of any adult witnesses. Although the cognitive development of children prevents the insertion of foreign bodies, the evidence is quite weak. In order to understand the psychological impact of foreign body insertion in children, further studies are needed. Among foreign bodies in ears, the most common was rubber, followed by seeds. In a similar study conducted in Brazil, beans were found to be the most common foreign body in the ear. ${ }^{11}$ Ryan et al reported beads to be most common foreign body in ear in pediatric patients. $^{12}$

External auditory foreign bodies of insects and arachnids cause great distress to patients due to otalgia and tinnitus. We observed seven patients with animate objects such as insects as foreign body ear. The crawling insects create an uncomfortable sense of irritation, while some bugs can attach to the tympanic membrane and cause extreme pain. ${ }^{13}$

A few patients had plastic or toys pieces lodged in their ears. A warning is usually included in all toys packages about the possibility of swallowing or aspirating small parts. However, most of the labels are in English. Therefore, there may be parents who aren't aware of these possibilities. Educating parents concerning the danger of exposing very young children to fragile toys is crucial.

In a report, Al-Juboori reported seven cases of students getting Bluetooth devices stuck in their ears on purpose during examinations to receive answers outside the examination hall by communicating through the device. Our study did not detect anything of the sort, but their occurrences and complications may be regarded as major otological challenges to be addressed in the future. Study participants ranged in age from one year old to sixty years old. ${ }^{14}$ 
An object that does not cause symptoms may remain in the canal for a lengthy period of time without causing significant discomfort. Foreign bodies may not be noticed by children unless observed at the time of onset. It can be difficult to remove an object that has been lodged for a long time. It is important to encourage patients to seek medical removal of a foreign body as early as possible, especially in the case of a vegetative or animate foreign body.

During the emergency setting, understanding the kinds of objects likely to be found in the external ear canal and knowing how to manage each of these should be of importance. Additionally, the frequency with which different objects are observed in different geographical areas must also be considered. By itself or through improper removal techniques, aural foreign bodies can damage a patient's tympanic membrane or middle ear. By attempting removal by an untrained person can cause a wide variety of complications. So, it is advised to refer the patients to otolaryngologist for the removal of aural foreign body. ${ }^{12}$

In this study, several limitations were present. Our study focused only on primary otological complaints, so it might understate otologic diagnosis associated with other presentations. Secondly, various sociodemographic factors that may be associated with otological complaints are missing from the study. Thirdly, as this is a hospital based study, the findings cannot be extrapolated to general population.

Thus, as part of a community-based study, we recommend that we analyze otological disorders and their patterns in the Nepali population.

\section{CONCLUSIONS}

Children with otological disorders are among the most common reasons for seeking medical care. Ear wax were most often found in our study and followed by foreign bodies. A disease-specific policy and devised guidelines is necessary to minimize the complications associated with poor hearing as we observed a high burden of otological disorders.

\section{Conflict of Interest: None.}

\section{NJHS}

\section{REFERENCES}

1. World Health Organization, author. WHO global estimates on prevalence of hearing loss. 2012. pp. 1

2. Rao RS, Subramanyam MA, Nair NS, Rajashekhar B. Hearing impairment and ear diseases among children of school entry age in rural South India. Int J Pediatr Otorhinolaryngol. 2002 Jun 17;64(2):105-10. doi: 10.1016/s0165-5876(02)00032-0. PMID: 12049823.

3. Auinger P, Lanphear BP, Kalkwarf HJ, Mansour ME. Trends in otitis media among children in the United States. Pediatrics. 2003 Sep;112(3 Pt 1):514-20. doi: 10.1542/peds.112.3.514. PMID: 12949276

4. Minovi A, Dazert S. Diseases of the middle ear in childhood. GMS Curr Top Otorhinolaryngol Head Neck Surg. 2014 Dec 1;13:Doc11. doi: 10.3205/cto000114 PMID: 25587371; PMCID: PMC4273172.

5. LeClair KL, Saunders JE. Meeting the educational needs of children with hearing loss. Bull World Health Organ. 2019 Oct 1;97(10):722-724. doi: 10.2471/ BLT.18.227561. Epub 2019 Sep 3. PMID: 31656339; PMCID: PMC6796661.

6. R Nepali, B Sigdel. Prevalence Of ENT Diseases In Children: Hospital Based Study. The Internet Journal of Otorhinolaryngology. 2012 Volume 14 Number 2.

7. Adhikari P, Kharel DB, Ma J, Baral DR, Pandey T, Rijal R, et al. Pattern of Otological Diseases in School Going Children of Kathmandu Valley. Int. Arch. Otorhinolaryngol. 2008;12(4):502-505

8. Thakur, S. K., S. K. Singh, B. Mahato, and A. Singh. "Ear Diseases Pattern and Hearing Impairment in the Eastern Nepal- A Study in a Combined Eye and Ear Set up”. Asian Journal of Medical Sciences, vol. 6, no. 5, Mar. 2015, pp. 51-55, doi:10.3126/ajms.v6i5.11621.

9. Kamfwa, Anthony Mwange and Victor Mwanakasal. "Pattern of pediatric Ear, Nose and Throat diseases at Arthur Davison Children's Hospital, Ndola, Zambia.” (2016).

10. Nisar J, Khaliq BA, Hanan A, Pampori RA. Pediatric ear, nose and throat emergencies Prevalence and management: A hospital-based study. Int J Adv Res 2016;4:1983-7

11. Balbani AP, Sanchez TG, Butugan O, Kii MA, Angélico FV Jr, Ikino CM, D’Antonio WE. Ear and nose foreign body removal in children. Int J Pediatr Otorhinolaryngol. 1998 Nov 15;46(1-2):37-42. doi: 10.1016/s0165-5876(98)00118-9. PMID: 10190703.

12. Ryan C, Ghosh A, Wilson-Boyd B, Smit D, O’Leary S. Presentation and management of aural foreign bodies in two Australian emergency departments. Emerg Med Australas. 2006 Aug;18(4):372-8. doi: 10.1111/j.1742-6723.2006.00865.x. PMID: 16842307

13. Harini, Padma \& Kudamala, Suneel. (2020). Aural foreign bodies and their management: our experience. International Journal of Otorhinolaryngology and Head and Neck Surgery. 6. 10.18203/issn.2454-5929.ijohns20201076.

14. Al-Juboori AN. Aural foreign bodies: descriptive study of 224 patients in Al-fallujah general hospital, iraq. Int J Otolaryngol. 2013;2013:401289. doi: 10.1155/2013/401289. Epub 2013 Dec 3. PMID: 24368915; PMCID: PMC3866709. 